\title{
Optimization of Vetiver Root Extract for Textile Finishing
}

\author{
Sakeena Naikwadi*, K.J. Sannapapamma and C.K. Venugopal \\ Department of Textile and Apparel Designing, College of Rural Home Science, University of \\ Agricultural Sciences, Dharwad, Karnataka, India \\ *Corresponding author
}

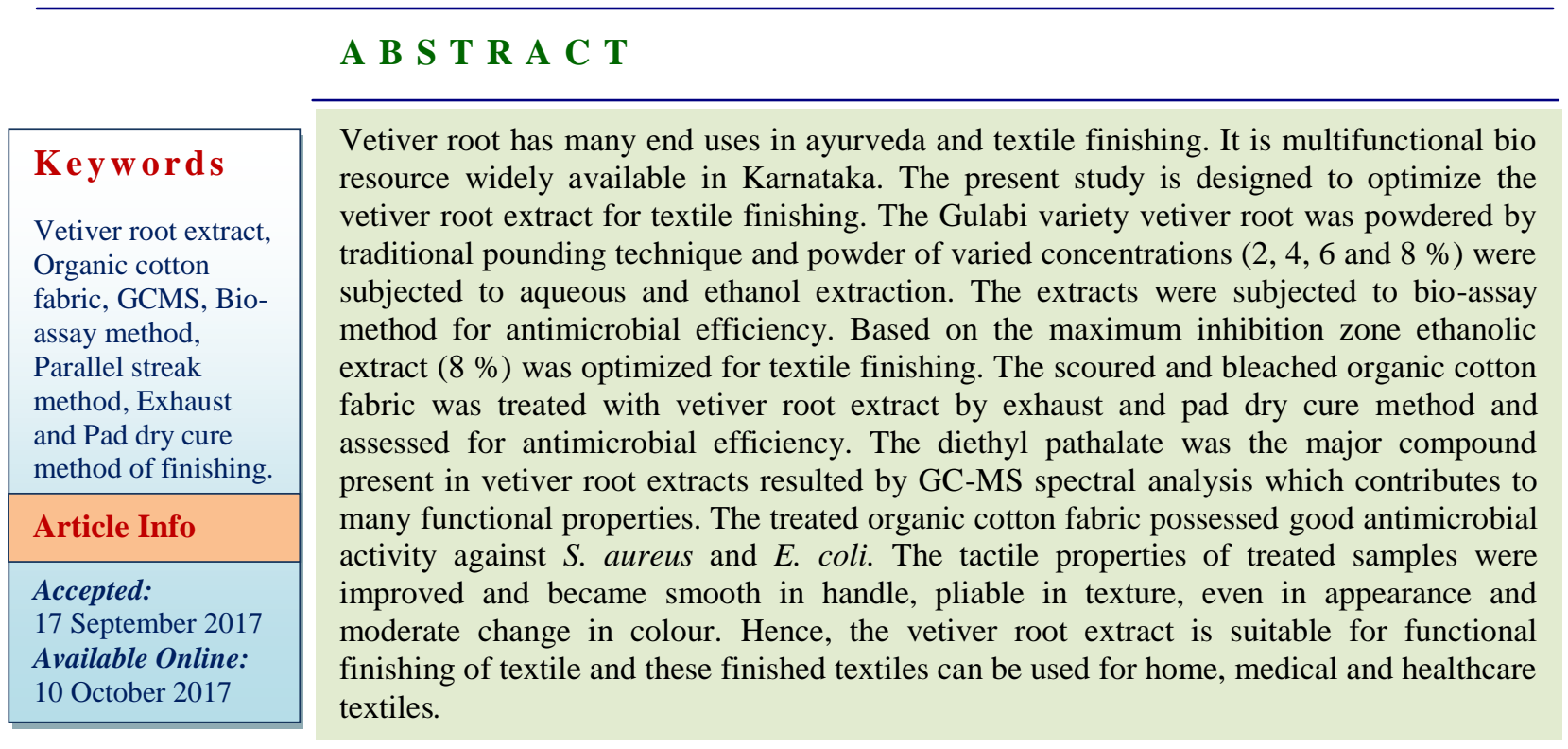

\section{Introduction}

Textile finishing is diversified sector due to the processed raw materials, manufacturing technique and products diversification. Trends in fashion cause continuous changes in colouring and functional finishes from the natural substrates comprises of those substances that are obtained from plants and animals possessed many advantages such as non-toxic, non-irritant, biodegradable, cost effective, easy availability (Christie and Sangeetha, 2016).

Vetiveria zizanioides belonging to the family Poaceae also known as Khas Khas, Khas or
Khus grass is native to India. Vetiveria derived from Tamil word "Vetiver" meaning "root that is dug out" and zizanioides means "by river side". As the name indicates, it is most commonly found along the water beds. Vetiver is a tall, tufted, perennial, scented grass, with a straight stem, long narrow leaves and erect culms up to 2 meters height and over 2.5 meters with flower head. The roots have a lacework root system are abundant, complex and extensive. The roots of Vetiveria zizanioides contain essential/volatile oil, known as Vetiver oil or 'khus oil'. Vetiver oil is used in traditional medicine and perfumery 
since ancient times. Indian tribes are using vetiver as a medium for curing mouth ulcer, hyper acidity, urinary tract infection, toothache, fever, boil, epilepsy, burn, snakebite, scorpion sting, rheumatism and headache (Kumar et al., 2014).

Ayurvedic literature mentioned that, plant is used as digestive, carminative stomachic, constipating, haematinic, expectorant, antispasmodic, antiasthmatic, antigout, anthelmentic, antimicrobical and diuretic. Vetiver fibre is one of natural fibres from the leaves and are lignocellulosic biocomposites comprising $\alpha$-cellulose-type-I, hemicellulose, lignin and low molecular weight compounds. Vetiver has many end uses such as aromatic, antifungal, cooling, antiemetic, diaphoretic, haemostatic, expectorant, diuretic, stimulant, hysteria, insomnia, skin diseases, asthma, amentia, amenorrhoea, antispasmodic, kidney problems, gall stones, mosquito repellent, tonic and antioxidant. It was recorded that, the vetiver has better antimicrobial properties under laboratory conditions (Krishnaveni, 2016). Hence, the present investigation is focused on optimization of vetiver root extract for textile application.

\section{Materials and Methods}

\section{Organic cotton fabric}

Plain hand woven organic cotton fabric interlaced with warp of single yarn (33s) and weft of 2 ply (2/33s) was procured from Department of Textile and Apparel Designing, College of Rural Home Science, University of Agricultural Sciences, Dharwad for functional finishing using vetiver root extract.

\section{Vetiver root}

The vetiver root (Gulabi variety) was procured from Department of Horticulture,
University of Agricultural Sciences, Dharwad (Plate 1). The collected vetiver roots were shade dried and cleaned. The dried and cleaned roots were crushed into fine powder by traditional pounding method (Plate 2 and $3)$.

\section{Method of extraction of vetiver root powder}

Extraction involves solvent penetration into herb cells, solubilisation of secondary metabolites and finally releasing the dissolved secondary metabolites in solvent of extraction. The solvent becomes enriched with extractive substances after penetration and the highest content of extractive substances is found in the solvent stock.

The two methods were used to extract the vetiver root powder i.e., aqueous and solvent extraction.

\section{Aqueous method of extraction}

The vetiver root powder of different concentrations viz., 2, 4, 6 and 8 grams were soaked in $100 \mathrm{ml}$ of water and kept it for overnight. The solution was centrifuged at $6000 \mathrm{rpm}$ for $30 \mathrm{~min}$ and the centrifuged solution was filtered using Whatsmann No. 1 filter paper. The filtered vetiver root extracts of different concentration was subjected to bio-assay method to assess the antimicrobial efficiency.

\section{Solvent method of extraction}

The vetiver root powder of different concentrations viz., 2,4,6 and 8 grams was dissolved in $100 \mathrm{ml}$ of diluted ethanol (ethanol : $80 \mathrm{ml}$ and water : $20 \mathrm{ml}$ ) kept it for overnight. These solutions were centrifuged at $6000 \mathrm{rpm}$ for $30 \mathrm{~min}$ at room temperature to get the bio active agents. The centrifuged solution was filtered using Whatsmann No. 1 
filter paper and subjected to bio-assay method to assess the antimicrobial efficiency.

\section{Bio-assay test}

Bio-assay is a method of determining the antimicrobial activity of bio-extracts against the test organism either bacteria or fungi. The vetiver root extract and vetiver oil was subjected bio assay test to determine the antimicrobial efficiency of vetiver extracts against the test organism gram positive bacteria Staphylococcus aureus and gram negative bacteria Escherichia coli. The paper disc method was adopted for diffusion of different concentration of vetiver extracts to determine the antimicrobial activity.

\section{Paper disc diffusion method}

The paper disc diffusion assay was used to test the antimicrobial efficiency of herbal extracts. Nutrient agar medium was prepared and mixed with inoculum suspensions which were prepared 24 hours old in nutrient broth. The prepared nutrient agar was poured into sterile petri plates and allowed to solidify. About $5 \mu \mathrm{l}$ of herbal extracts were loaded to sterile paper discs and placed on surface of agar media. The plates were incubated for 24 hours at $37{ }^{0} \mathrm{C}$. The zone of inhibition were recorded in millimetres and based on the maximum zone of inhibition 8 per cent ethanolic extract of vetiver root concentration was optimized for finishing of organic cotton fabric.

GCMS analysis of vetiver root extract and vetiver essential oil

Gas Chromatography Mass Spectrometry (GCMS) is a powerful technique to provide the identification of compounds with low detection limits and potential for quantitative analysis. The components identification of vetiver root extract was achieved by using
Shimadu GC-2010 gas chromatograph coupled with QP2010 mass spectrometer with following test conditions.

Column: DB 5MS (30 m x $0.25 \mathrm{~mm} \times 0.25)$

Over temperature: $130{ }^{0} \mathrm{C}(5$ mins. $) @ 2{ }^{0} \mathrm{C}$ /min., $180{ }^{0} \mathrm{C}$ (0 mins.) @ $15{ }^{0} \mathrm{C} / \mathrm{min} ., 325{ }^{0} \mathrm{C}$ (0 mins.)

Injector Temperature: $280{ }^{0} \mathrm{C}$

Detector Temperature: $280{ }^{0} \mathrm{C}$

\section{Exhaust method of finishing}

A known amount of scoured and bleached organic cotton fabric was immersed into finishing bath which was prepared by using below mentioned recipe. The material was immersed in the finishing bath and stirred continuously for 30 minutes. The bath temperature was slowly increased up to $50{ }^{0} \mathrm{C}$. After 30 minutes the fabric was taken out from the bath, squeezed and dried under shade.

\section{Recipe}

MLR: 1:30

Citric acid: $8 \%$ owf

Vetiver root extract: $8 \%$ owf

Temperature: 500C,

Time: $30 \mathrm{~min}$

\section{Pad dry cure method of finishing}

This process comprised three steps i.e. padding, drying and curing. The fabric is first immersed in the finishing solution which contains a required amount of vetiver root extract cross linking agent (recipe as mentioned below). The treated fabric was passed between the rollers two to three times at a uniform pressure for better penetration of finishing agent and to squeeze out excess 
liquid from the fabric. The fabric is then dried and cured in a curing chamber by maintaining the required temperature and time.

\section{Recipe}

MLR: 1:10

Citric acid: $8 \%$ owf

Vetiver root extract: $8 \%$ owf

Temperature: 440C,

Pressure: $1 \mathrm{~kg} / \mathrm{cm} 2$

\section{Assessment of antimicrobial activity}

Antimicrobial finishing of textiles is one of the functional properties that resist the growth of the bacteria on the fabric surface. Antimicrobial activity of the treated fabrics were assessed by AATCC 147 test method used for determining the antimicrobial activity of the treated samples.

\section{Assessment of tactile properties of finished organic cotton fabrics}

Vetiver root extract treated organic cotton fabrics were assessed for tactile properties where the handle, texture, appearance and color change properties was rated by the 30 panel members. Among the total samples, 15 respondents belong to teachers of University Agricultural Sciences, Dharwad and 15 respondents belong to student of College of Rural Home Science, University Agricultural Sciences, Dharwad.

\section{Results and Discussion}

\section{GCMS spectral analysis of ethanolic extracts of vetiver root powder}

Ethanolic extract of vetiver root powder of GCMS spectra exhibited 22 compounds with varied area percentage at different retention time with different base $\mathrm{m} / \mathrm{z}$ peak as illustrated in Table 1 and Figures 1 \& 2 .
Among the compounds of the vetiver root extract, the area percentage of Diethyl pathalate was found to be greater i.e., 87.73 per cent at retention time 13.670 with base $\mathrm{m} / \mathrm{z} 149.05$ than the other compounds. Further, 4.05 per cent area was attributed by 7- Isopropyl dimethyl carboxylic acid at R. time 32.099 with base $\mathrm{m} / \mathrm{z} 256.15$ followed by 2-Butanone 4-trimethyle cyclohexen (1.21 $\%)$, phenanthrene carboxylic acid (1.03\%), Naphthalene pentanoic acid (0.99 \%), 1phenanthrene carboxylic acid and 1 cyclohexanone 2-methyl oxobuty (0.89\%). However, other compounds present in the powder were ranged from $0.00-1.00$ per cent viz., Methyl dehydroabietat $(0.08 \%)$, benzene (0.47 \%), 1- phenanthrene carboxylic acid $(0.35 \%)$, morpholene and benzo amide $(0.18$ $\%)$, 2-propyne-1-cyclopentyl and ethyl 33 diethoxypropionat $(0.17 \%)$, propylhexanal, cyclohexanone and 1-4 cyclohexadiene $(0.11$ $\%)$, benzestrol $(0.15 \%)$, trimethyl orthobutyrat (0.06) and L-2-Bromo alpha benzyl alcohol (0.05\%). However, diethyl phthalate was the major compound present in the vetiver root and it has a good source of plasticizer can be effectively used in textile finishing to improve the elongation and crease recovery properties of the fabric. The second major compound 7- Isopropyl dimethyl carboxylic acid present in vetiver root which acts as precursor, reducing agent and used in production of polymers and soaps. Cyclohexanone is also present in vetiver root which is used as precursor in production of Nylon 6, 6 and Nylon 6. It has many uses include wood stains, paint and varnish removers, spot remover, degreasing of metals, polishes, levelling agents, dyeing and delustering silk, lubricating oil additives, solvent for herbicides, cellulosic, natural and synthetic resins, waxes, fats, etc. The vetiver root has rich source of many organic compound which are very much useful for textile wet processing. The same results are in line with Kumar and Gayathri (2016) stated 
that the GCMS spectra of ethanolic extract from Vetiveria zizanoides (EVZ) showed the presence of numerous active compounds including Vetiverone, trans-Isoeugenol, 9,10Dimethyltricylo, Isolongifolene, 9, 10dehydro and Naphthalene carboxylic acid etc.

\section{Optimization of vetiver root extract through Bioassay method}

Antimicrobial efficiency of vetiver root extracts against $S$. aureus and E.coli through Bio-assay method

Among the concentrations, 8 per cent root extract in ethanol and aqueous extraction showed greater zone of inhibition against gram positive organism $S$. aureus and gram negative organism E. coli. As the concentration of extract increases, the presence of bio-active component may be more and yields maximum zone of inhibition against $S$. aureus and E. coli.

Irrespective of methods of extraction and various concentrations of vetiver root extract, the greater zone of inhibition was found in ethanol extract against $S$. aureus and E. coli compared to aqueous extraction. Further, in solvent extraction method, 8 per cent concentration exhibited greater zone of inhibition i.e., $14.4 \pm 0.96$ and $11.6 \pm 0.96$ against $S$. aureus and $E$. coli followed by 6 per cent ( $S$. aureus: $13.5 \pm 1.08$ and E. coli: $10.9 \pm 1.10), 4$ per cent $(S$. aureus: $10.7 \pm$ 1.33 and E. coli: $10.3 \pm 0.82$ ) and 2 per cent concentrations $(S$. aureus: $6.6 \pm 0.96$ E. coli: $5.5 \pm 0.52)$ respectively. Similar results were observed among the various concentrations of vetiver root extract through aqueous method i.e., the 8 per cent of vetiver root extract registered greater zone of inhibition against $S$. aureus $(8 \pm 1.82)$ and $E$. coli $(7.55 \pm 0.88)$ followed by 6 per cent of concentration $(S$. aureus : $6 \pm 0.94$ and $E$. coli : No zone). However, no inhibition zone was found in 4 per cent and 2 per cent concentration of vetiver root extracts (Table 2 and Plate 4, 5).

Antimicrobial activity of the vetiver extract in ethanol and aqueous extract suggested that, vetiver root of 8 per cent concentration was the most effective concentration for textile application. Hence, 8 per cent concentration (owf) was used for finishing organic cotton fabrics. Dhanalaxmi (2014) in her study revealed that, irrespective of the source, 100 per cent concentrated extract showed greater zone of inhibition against $S$. aureus and $E$. coli than 10 and 5 per cent of extract concentration. Besides the antimicrobial activity is also influenced by a couple of reasons, like the solvent used, phenolics present in the material source, extraction protocol, etc. Christie and Sangeetha (2016) reported that 100 per cent solution was exhibited greater antimicrobial efficacy compare to 75 and 50 per cent solution and further used for fabric finishing.

\section{Antimicrobial efficiency of vetiver root extract finished organic cotton fabrics}

Parallel streak method was adapted to know the antibacterial efficiency of treated fabrics with vetiver root extracts through exhaust and pad dry cure method against gram positive organism Staphylococcus aureus and gram negative organism Escherichia coli as reported below (Table 3 and Plate 6, 7).

The vetiver root extract treated fabric by pad dry cure method showed maximum antimicrobial efficiency against gram positive organism $S$. aureus and gram negative organism $E$. coli with zone of inhibition 10.1 \pm 0.651 and $8.4 \pm 1.08$ compared to the fabric treated with vetiver root extract through exhaust method against $S$. aureus and E. coli with zone of inhibition $7.3 \pm 0.570$ and $6.8 \pm$ 0.836 respectively. 
Table.1 GCMS spectral analysis of ethanolic extracts of vetiver root powder

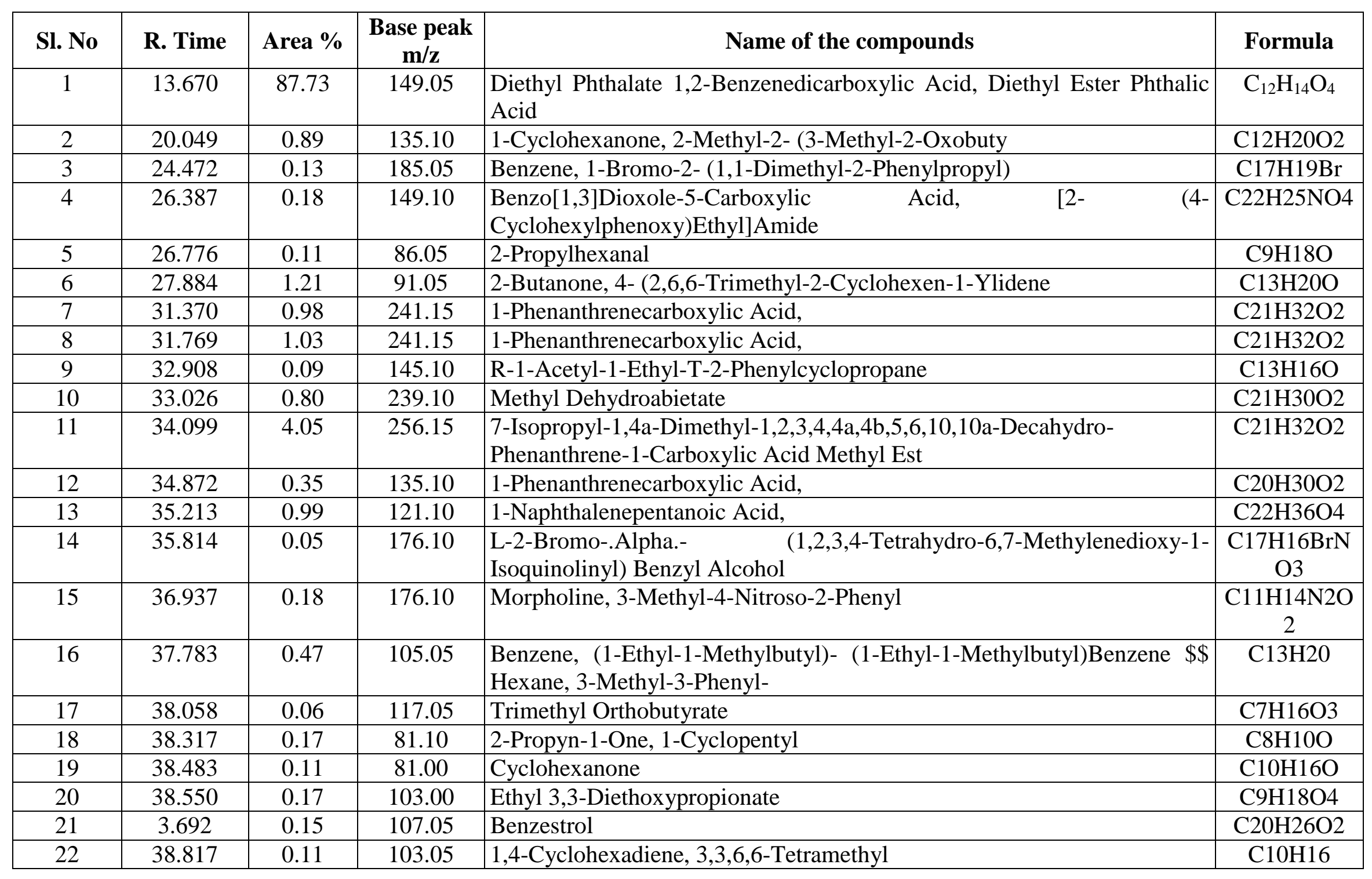


Table.2 Antimicrobial efficiency of vetiver root extracts against

S.aureus and E.coli through bio-assay method

\begin{tabular}{|c|c|c|c|}
\hline \multirow{2}{*}{ Organisms } & \multirow{2}{*}{ Concentrations } & \multicolumn{2}{|c|}{ Extraction Methods } \\
\cline { 2 - 4 } & & Aqueous & Ethanol (80 \%) \\
\hline \multirow{3}{*}{ Staphylococcus aureus } & Control & NI & $6.6 \pm 0.96$ \\
\cline { 2 - 4 } & $2 \%$ & NI & $9.1 \pm 0.99$ \\
\cline { 2 - 4 } & $4 \%$ & NI & $10.7 \pm 1.33$ \\
\cline { 2 - 4 } & $6 \%$ & $6 \pm 0.94$ & $13.5 \pm 1.08$ \\
\cline { 2 - 4 } & $8 \%$ & $\mathbf{8} \pm \mathbf{1 . 8 2}$ & $\mathbf{1 4 . 4} \pm \mathbf{0 . 9 6}$ \\
\hline \multirow{3}{*}{ Escherichia coli } & Control & NI & $5.5 \pm 0.52$ \\
\cline { 2 - 4 } & $2 \%$ & NI & $1.6 \pm 0.96$ \\
\cline { 2 - 4 } & $4 \%$ & NI & $10.9 \pm 1.10$ \\
\cline { 2 - 4 } & $6 \%$ & $\mathbf{7 . 5 5} \pm \mathbf{0 . 8 8}$ & $\mathbf{1 1 . 6} \pm \mathbf{0 . 9 6}$ \\
\cline { 2 - 4 } & $8 \%$ & & \\
\hline
\end{tabular}

Figures in parentheses indicate Mean \pm Standard deviation

Note: NI- No inhibition

Table.3 Antimicrobial efficiency of vetiver finished samples and wash durability

\begin{tabular}{|l|l|l|}
\hline \multirow{2}{*}{ Samples } & Zone of inhibition (mm) \\
\cline { 2 - 3 } & S. aureus & E. coli \\
\hline Vetiver root extract finished organic cotton by exhaust method & $\mathbf{7 . 3} \pm \mathbf{0 . 5 7 0}$ & $\mathbf{6 . 8} \pm \mathbf{0 . 8 3 6}$ \\
\hline Vetiver root extract finished organic cotton fabric by pad-dry-cure method & $\mathbf{1 0 . 1} \pm \mathbf{0 . 6 5 1}$ & $\mathbf{8 . 4} \pm \mathbf{1 . 0 8}$ \\
\hline
\end{tabular}

Figures in parentheses indicate Mean \pm Standard deviation

Table.4 Tactile properties of vetiver finished organic cotton fabrics

\begin{tabular}{|c|c|c|c|c|}
\hline Type of respondents & \multicolumn{2}{|c|}{ Parameters } & VEE & VEP \\
\hline \multirow{9}{*}{ Teachers } & \multirow{2}{*}{ Handle } & Smooth & $11(73.33)$ & $14(93.33)$ \\
\hline & & Rough & $04(26.66)$ & $01(6.66)$ \\
\hline & \multirow{2}{*}{ Texture } & Pliable/ flexible & $12(80.00)$ & $14(93.33)$ \\
\hline & & Stiff & $03(20.00)$ & $01(6.66)$ \\
\hline & \multirow{2}{*}{ Appearance } & Evenness & $11(73.33)$ & $08(53.33)$ \\
\hline & & Uneven (patchy) & $44(26.66)$ & $07(46.66)$ \\
\hline & \multirow{3}{*}{ Change in color } & Fully change & $01(6.66)$ & $01(6.66)$ \\
\hline & & Moderate change & $11(73.33)$ & $13(86.66)$ \\
\hline & & No change & $03(20.00)$ & $01(6.66)$ \\
\hline \multirow{9}{*}{ Students } & \multirow{2}{*}{ Handle } & Smooth & $10(66.66)$ & $10(66.66)$ \\
\hline & & Rough & $05(33.33)$ & $05(33.33)$ \\
\hline & \multirow{2}{*}{ Texture } & Pliable/ flexible & $10(6.66)$ & $11(73.33)$ \\
\hline & & Stiff & $5(33.33)$ & $04(26.66)$ \\
\hline & \multirow{2}{*}{ Appearance } & Evenness & $12(80.00)$ & $08(53.33)$ \\
\hline & & Uneven (patchy) & $03(20.00)$ & $07(46.66)$ \\
\hline & \multirow{3}{*}{ Change in color } & Fully change & $0(0.0)$ & $03(20.00)$ \\
\hline & & Moderate change & $13(86.66)$ & $11(73.33)$ \\
\hline & & No change & $02(13.33)$ & $01(6.66)$ \\
\hline
\end{tabular}

Figures in parentheses indicate frequency and percentage

Note

VEE: Vetiver root extract finished organic cotton by exhaust method

VEP: Vetiver root extract finished organic cotton fabric by pad-dry-cure method

VME: Vetiver oil microcapsules finished organic cotton fabric by exhaust method

VMP: Vetiver oil microcapsules finished organic cotton fabric by pad-dry-cure method 


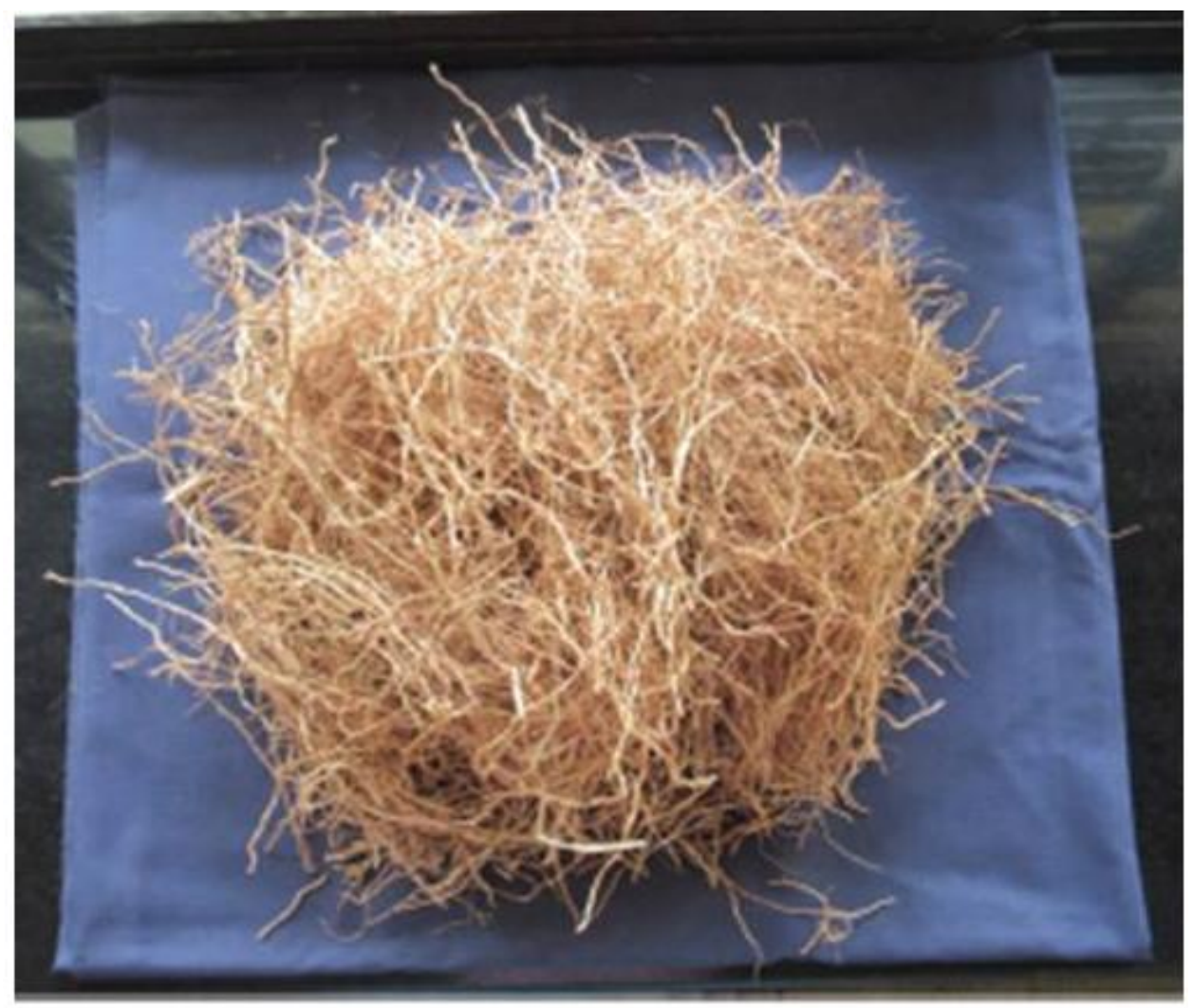

Plate 1: Vetiver root

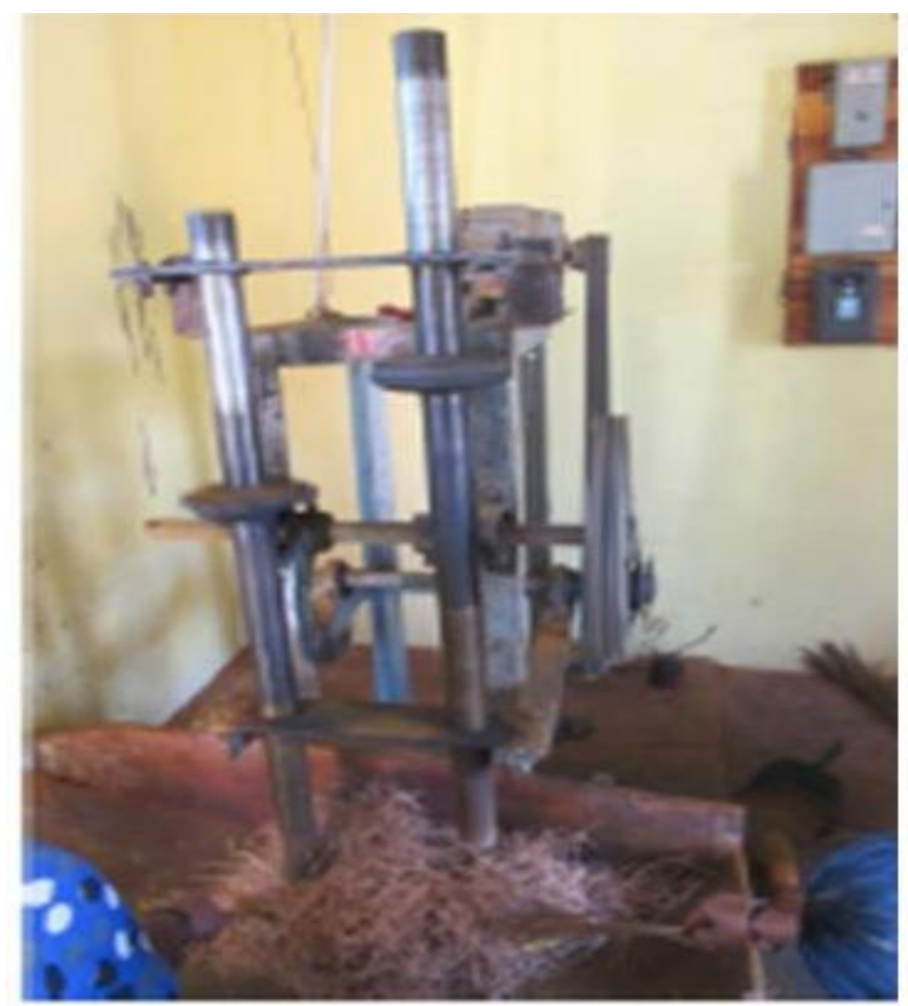

Piate 2: Pounding technique of vetiver root 


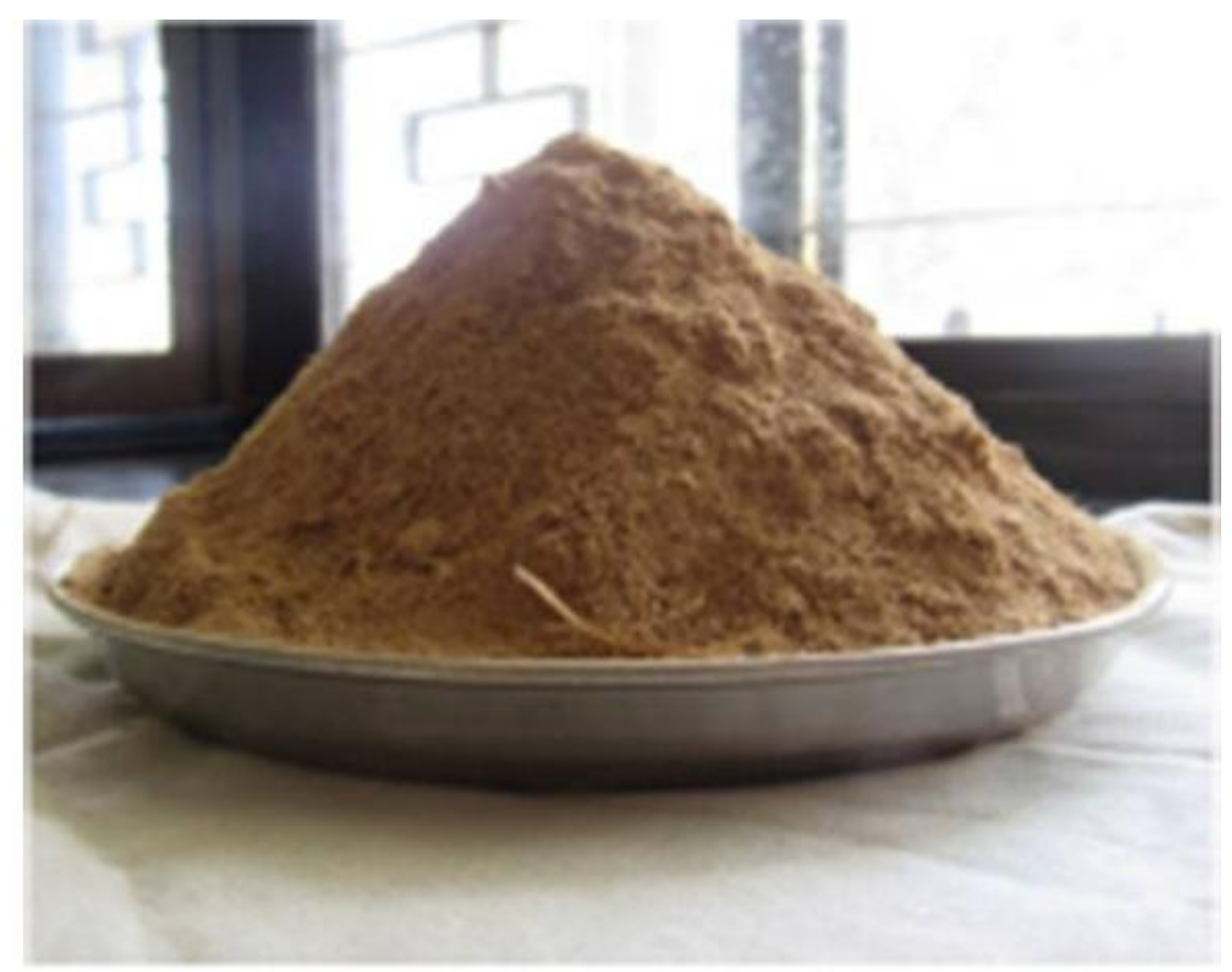

Plate 3: Vetiver root powder

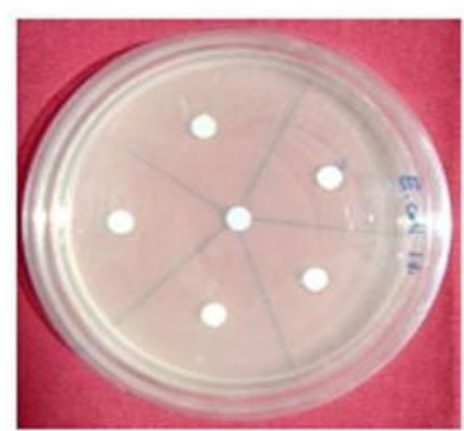

$2 \%$ vetiver root extract

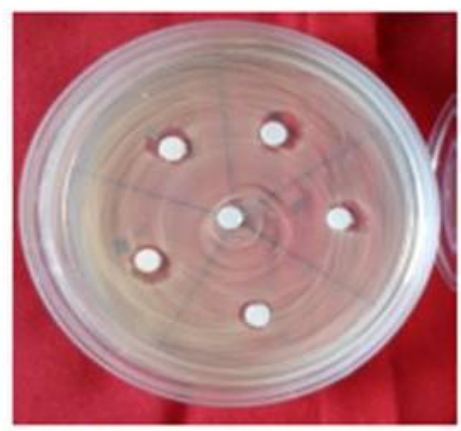

$6 \%$ vetiver root extract

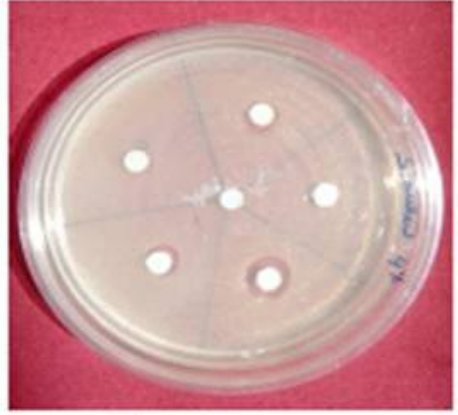

$4 \%$ vetiver root extract

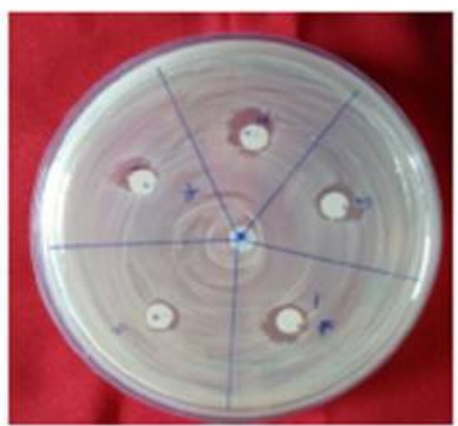

$8 \%$ vetiver root extract

Plate 4: Antimicrobial eficiency of vetiver root extracts against $S$.aureus through bio assay method 


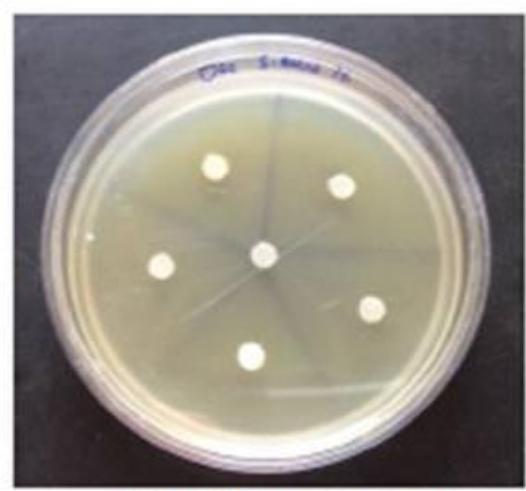

$2 \%$ vetiver root extract

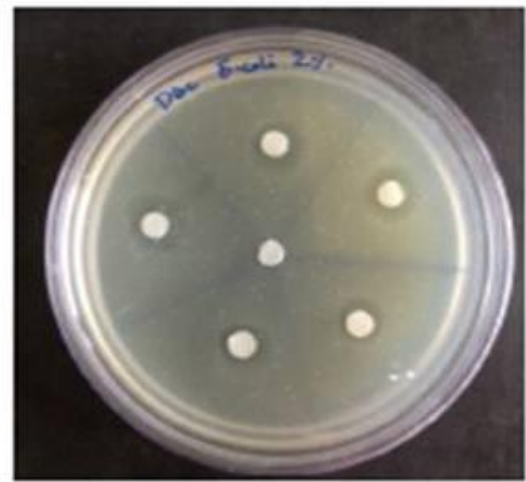

$6 \%$ vetiver root extract

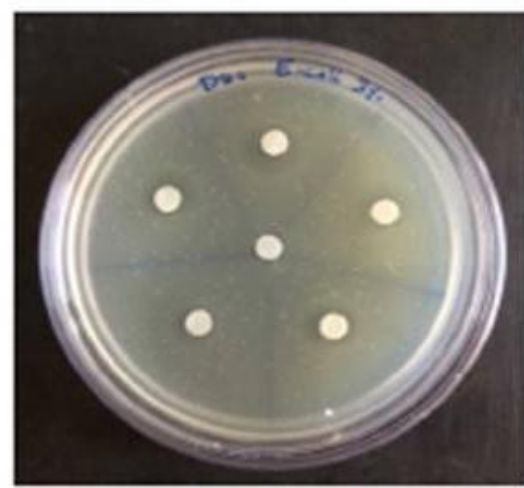

$4 \%$ vetiver root extract

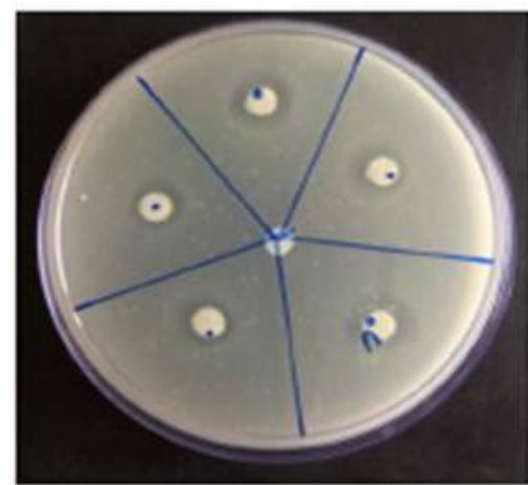

$8 \%$ vetiver root extract

Plate 5: Antimicrobial eficiency of vetiver root extracts against $E$-cot through bio-assay method

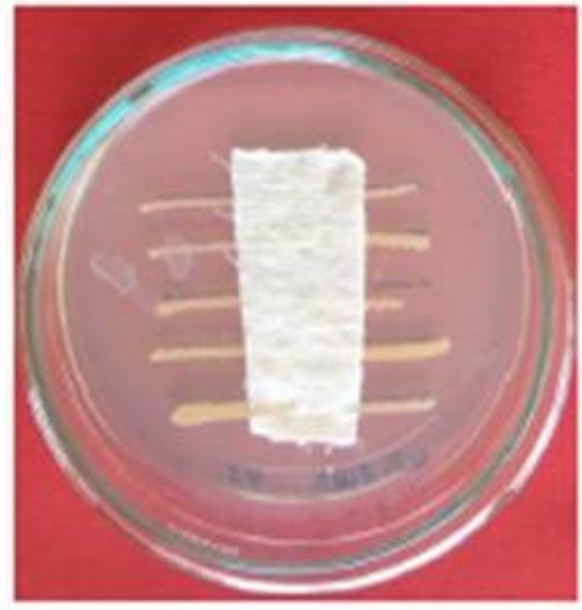

Control(Organic cotton fabric)

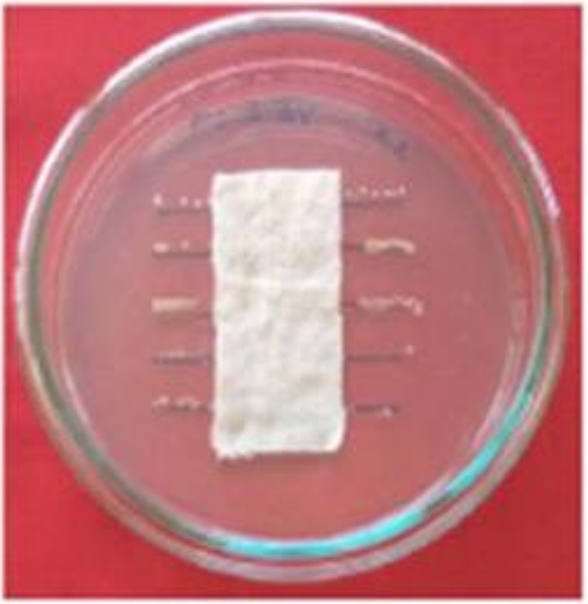

Vetiver root extract finished (Exhaust)

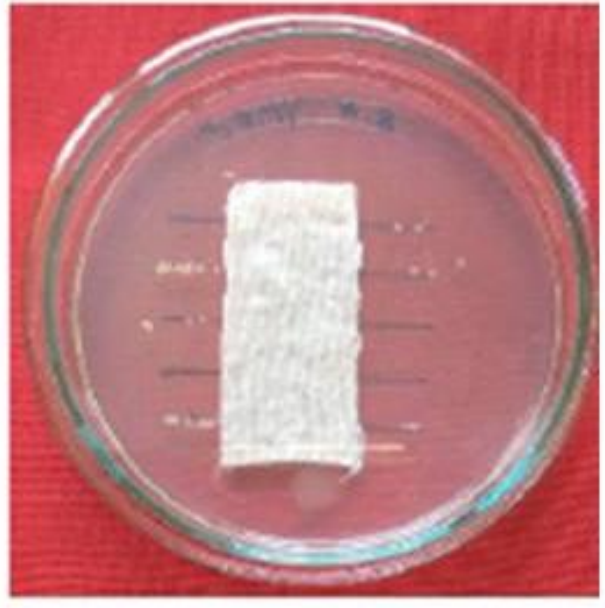

Vetiver root extract Finished (Pad dry cure)

Plate 6 : Antimicrobial eficiency of vetiver finished organic cotton fabrics against.S.aureus 


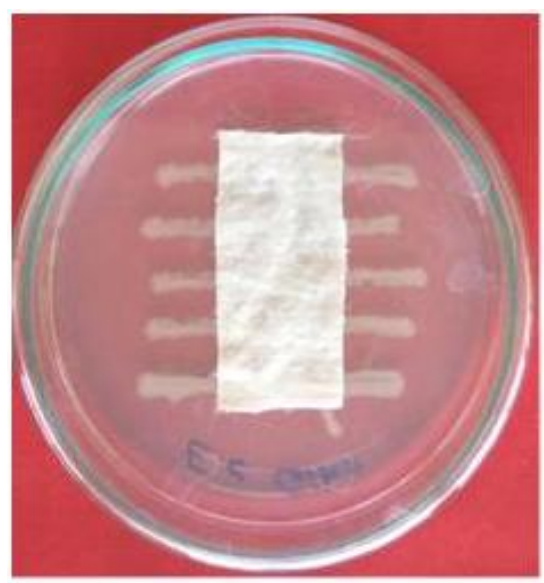

Control(Organic cotton fabric)

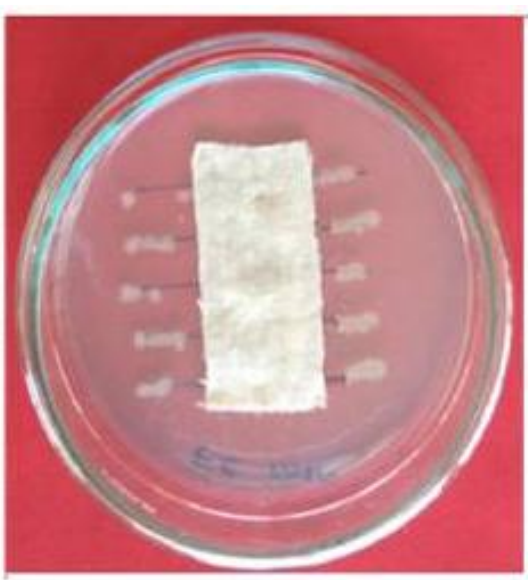

Vetiver root extract finished (Exhaust)

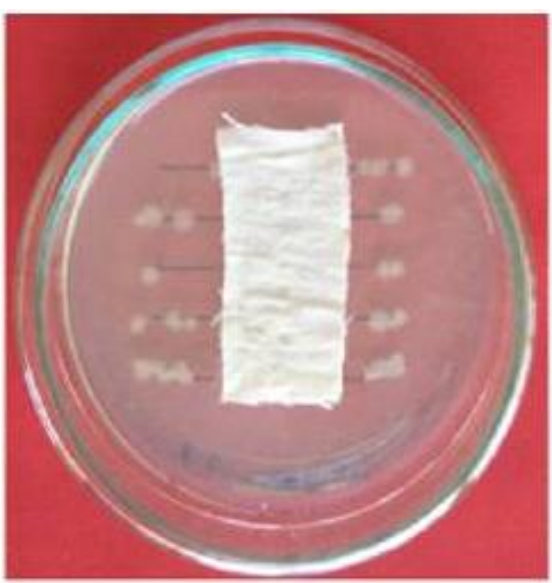

Vetiver root extract Finished (Pad dry cure)

Phate 7 : Antimicrobial eficiency of vetiver finished organic cotton fabrics against $E$ co $h$

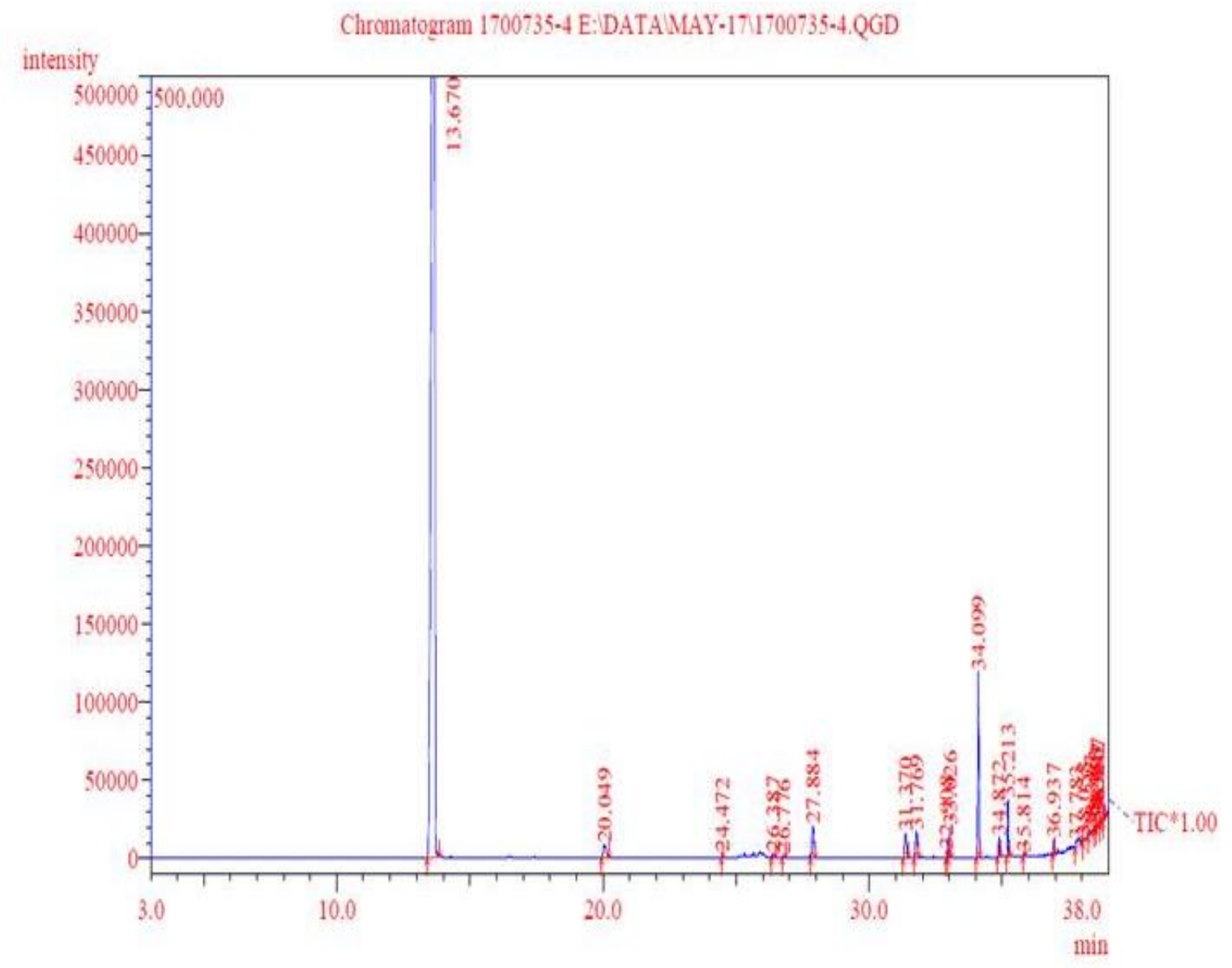

Fig. 1: GCMS spectral analysis of ethanolicertracts of vetiver root powder 
Fig.2 Chemical structure of major compound present in vetiver root powder

\begin{tabular}{|l|l|}
\hline \multicolumn{1}{|c|}{ Name of the Compound } & Formula \\
\hline Diethyle phthylate & $\left.\mathrm{C}_{12} \mathrm{H}_{14} \mathrm{O}_{4}\right)$ \\
\hline $\begin{array}{l}\text { 7-Isopropyl-1,4a-Dimethyl- } \\
\text { 1,2,3,4,4a,4b,5,6,10,10a- } \\
\text { Decahydro-Phenanthrene-1- } \\
\text { Carboxylic Acid Methyl Est }\end{array}$ & $\mathrm{C}_{21} \mathrm{H}_{32} \mathrm{O}_{2}$
\end{tabular}

This may be due the of absorption and deeply deposition of vetiver root extract in the fabric sample by the pressure of rollers, where the fabric passed between two rollers for fixing of finishing agents in the polymer structure of fabric during pad dry cure finishing process.

The vetiver root extract treated fabrics through exhaust and pad dry cure method exhibited maximum zone of inhibition against gram positive organism $S$. aureus than gram negative organism E. coli. This may be due to the gram positive bacteria are more susceptible to natural herbal plants extracts compared to gram negative bacteria.

The same results are in line with Mohanraj et al., (2011) stated that the fabric treated with Vitex negudo extract registered zone of inhibition against two microbes, where in higher zone was observed in the case of gram positive bacteria. S. aureus as compared to gram negative bacteria $E$. coli. Thilagavathi and Kannaian (2010) reported that the fabric treated with geranium extract showed higher zone of inhibition against $S$. aureus compared to $E$. coli due to the $S$. aureus is more sensitive to geranium extract compared to $E$. coli.

\section{Tactile properties of vetiver finished} organic cotton fabrics

Among the groups, a majority of the teachers and students opined that, the handle property of finished samples found to be smooth in handle, pliable in texture, evenness in appearance and moderately colour change.

It is apparent from the Table 4 that, majority of the respondents (teachers and students) opined that, the treated samples (VEE:73.33/66.66 \% and VEP:93.33/66.66 $\%)$ possessed smooth handle followed by rough handle (VEE:26.66/33.33 \% and VEP:06.66/33.33 \%) respectively. 
In case of textural property of treated samples, majority of respondents stated that, the treated samples possessed pliable in handle under the category of teachers; VEE (80.00) and VEP (93.33) and students; VEE (6.66) and VEP (73.33) due to the presence of major amount of plasticizer i.e., Diethyl pathalate compound.

Most of the respondents opined that, the treated samples possessed evenness in appearance under the category of teachers; VEE (73.33) and VEP (53.33) and students; VEE (80.00) and VEP (53.33). This may be due to uniform sublimation of finishing agents in exhaust method of finishing.

Majority of teachers (VEP: $86.66 \%$ ) opined that there was a moderate change in colour of treated fabric followed by fully change in colour (VEE: $06.00 \%$ ) and no change (VEP: $06.66 \%)$ respectively. Whereas in case of VEE treated fabric, majority of teachers opined that moderate change in colour (73.33 $\%)$ followed by no change $(20.00 \%)$ and fully change $(06.66 \%)$ respectively, due to the yellowish pigments present in the root extract.

However, majority of students opined that (73.33 \%) moderate change in colour was observed in VEP treated fabrics followed by fully change $(20.00 \%)$ and no change (06.66 $\%)$ respectively. Whereas in the VEE fabric, majority of students opined moderate change $(86.66 \%)$ followed by no change $(13.33 \%)$ respectively.

Majority of respondents opined that treated fabrics showed smooth in handle property followed by rough, pliable in texture evenness in appearance and moderately change in colour. This is because of finishing agents i.e., vetiver root extracts deposited on the surface of the treated fabrics which in turn improves the tactile properties due to the presence of major compound like diethyl pathalate, 7Isopropyl dimethyl carboxylic acid and 2butanone 4-trimethyle cyclohexen.

Vetiver has traditionally been used as medicinal and aromatic plant in many places of Uttar Kannada district. This bio-resource is mainly used in medicine, aroma therapy and few handicraft centres involved in preparation of different handicrafts. According to GCMS spectral analysis, the major bio active constituents found in vetiver root extracts were diethyl pathalate, 7- Isopropyl dimethyl carboxylic acid, 2-butanone 4-trimethyle cyclohexen, phenanthrene carboxylic acid, naphthalene pentanoic acid, 1-phenanthrene carboxylic acid and 1 cyclohexenone 2methyl oxobuty. The highest percentage concentration of Vetiveria zizanioides root extracts $(8 \%)$ showed good antibacterial activity compared to other concentrations.

Vetiver root extract $(8 \%)$ treated organic cotton fabric through pad dry cure method showed good antibacterial activity against the gram positive and gram negative bacteria compared organic cotton fabric treated with to vetiver root extract through exhaust method.

The inhibition zone of treated samples was found to be greater against gram positive bacteria than gram negative bacteria due to the gram positive bacteria are more susceptible to natural herbal plants extracts compared to gram negative bacteria. The tactile properties of the treated samples has been improved and it became smooth in handle and pliable in texture due to the presence of diethyl pathalate, even in appearance and moderate change in colour compared to control sample. The bio active constituents of vetiver root extracts registered free radical scavenging, anti-inflammatory, antimicrobial and aromatic properties which are suitable for development of healthcare and technical textiles. 


\section{References}

Christie, K., and Sangeetha, K., 2016, A Comparative study on antimicrobial finish using Pisidium guajava leaf extraction on cotton, organic cotton and bamboo fabrics. Int. Conf. on Inform. Engg, Mngt and Security, 101-106.

Dhanalaxmi, D., 2014, Eco-friendly antimicrobial finishes on natural colour cotton knits. Ph. D. Thesis, Uni. Agric. Sci. Dharwad (India).

Krishnaveni, V., 2016, Analysis of chemical components and antimicrobial activity on vetiver extract for home textile applications. J. Textile Sci. Eng., 6(3): 1-3.

Kumar, M., Ruckmani, A., Saradha, S., Arunkumar, R., Lakshmipathy, R., Madhavi, E. and Devi, T., 2014,
Evaluation of antiepileptic activity of Vetiveria zizanioides oil in mice. Int. J. Pharm. Sci. Rev. Res., 25(2): 248-251.

Kumar, S., and Gayathri, K., 2016, Chemical characterization of Vetiveria zizaniodes linn root. Int. J. Pharm. Bio. Sci., 7(4): 689-695.

Mohanraj, S., Vanathi, P., Sowbarniga, N. and Saravanan, D., 2011, Antimicrobial effectiveness of Vitex negundo leaf extracts. Indian J. Fibre Text. Res., 37 (02): 389-392.

Thilagavathi, G., and Kannaian, T., 2010, Combined antimicrobial and aroma finishing treatment for cotton, using microencapsulated geranium (Pelargonium graveolens L' Herit. ex Ait.) leaves extract. Indian J. Nat. Prod. Reso, 1 (3): 348-352.

\section{How to cite this article:}

Sakeena Naikwadi, K.J. Sannapapamma and Venugopal, C.K. 2017. Optimization of Vetiver Root Extract for Textile Finishing. Int.J.Curr.Microbiol.App.Sci. 6(10): 2009-2022. doi: https://doi.org/10.20546/ijcmas.2017.610.238 